\title{
Lung tumor exosomes induce a pro- inflammatory phenotype in mesenchymal stem cells via NFkB-TLR signaling pathway
}

\author{
Xiaoxia $\mathrm{Li}^{1 \dagger}$, Shihua Wang ${ }^{1 \dagger}$, Rongjia Zhu, Hongling $\mathrm{Li}^{1}$, Qin Han ${ }^{1 *}$ (D) and Robert Chunhua Zhao ${ }^{1,2^{*}}$
}

\begin{abstract}
Background: In tumor microenvironment, a continuous cross-talk between cancer cells and other cellular components is required to sustain tumor progression. Accumulating evidence suggests that exosomes, a novel way of cell communication, play an important role in such cross-talk. Exosomes could facilitate the direct intercellular transfer of proteins, lipids, and miRNA/mRNA/DNAs between cells. Since mesenchymal stem cells (MSCs) can be attracted to tumor sites and become an important component of the tumor microenvironment, there is an urgent need to reveal the effect of tumor exosomes on MSCs and to further explore the underlying molecular mechanisms.

Methods: Exosomes were harvested from lung cancer cell line A549 and added to MSCs. Secretion of inflammationassociated cytokines in exosome-treated MSCs were analyzed by RT-PCR and ELISA. The growth-promoting effect of exosome-treated MSCs on lung tumor cells was evaluated by in vivo mouse xenograft model. Signaling pathway involved in exosomes-treated MSCs was detected by PCR array of human toll-like receptor signaling pathway, RT-PCR, and Western blot.
\end{abstract}

Results: Data showed that lung tumor cell A549-derived exosomes could induce a pro-inflammatory phenotype in MSCs named P-MSCs, which have significantly elevated secretion of IL-6, IL-8, and MCP-1. P-MSCs possess a greatly enhanced ability in promoting lung tumor growth in mouse xenograft model. Analysis of the signaling pathways in P-MSCs revealed a fast triggering of NF-KB. Genetic ablation of Toll-like receptor 2 (TLR2) by siRNA and TLR2-neutralizing antibody could block NF-kB activation by exosomes. We further found that Hsp70 present on the surface of lung tumor exosomes contributed to the induction of P-MSCs by A549 exosomes.

Conclusions: Our studies suggest a novel mechanism by which lung tumor cell-derived exosomes induce proinflammatory activity of MSCs which in turn get tumor supportive characteristics.

Keywords: Exosomes, MSCs, Tumor-supportive, Inflammation, NF-KB, TLR2, HSP70

\section{Background}

Tumor microenvironment has a close relationship with tumor development and metastasis [1]. A complex milieu of non-malignant cells compose tumor microenvironment, contributing to tumor progression by interactions

\footnotetext{
*Correspondence: hanqinhanqin@126.com; zhaochunhua@vip.163.com ${ }^{\dagger}$ Equal contributors

${ }^{1}$ Center of Excellence in Tissue Engineering, Key Laboratory of Beijing, Institute of Basic Medical Sciences and School of Basic Medicine, Chinese Academy of Medical Sciences and Peking Union Medical College, Beijing, People's Republic of China

${ }^{2}$ Center of Translational medicine Peking Union Medical College Hospital, Chinese Academy of Medical Sciences and Peking Union Medical College, Beijing, People's Republic of China
}

C $2016 \mathrm{Li}$ et al. Open Access This article is distributed under the terms of the Creative Commons Attribution 4.0 International License (http://creativecommons.org/licenses/by/4.0/), which permits unrestricted use, distribution, and reproduction in any medium, provided you give appropriate credit to the original author(s) and the source, provide a link to the Creative Commons license, and indicate if changes were made. The Creative Commons Public Domain Dedication waiver (http:// creativecommons.org/publicdomain/zero/1.0/) applies to the data made available in this article, unless otherwise stated. with tumor cells and/or with each other [2]. Mesenchymal stem cells (MSCs) are an important component of these cells. MSCs are defined as multipotent stem cells that have the capacity to give rise to adipocytes, osteoblasts, and chondrocytes [3]. They can be isolated from a number of tissues including bone marrow, adipose tissue, and umbilical cord blood. Although the function of naïve MSC in tumor remains controversial, the tumor-supporting roles of tumor associated mesenchymal stem cells have been acknowledged [4]. This may be attributed to a longtime "education" by tumor cells. 
Tumor cells can modulate tumor stromal cells through intercellular communications. This process can be mediated through direct cell contact or through secreted signaling factors (cytokines, chemokines, and growth factors) and microvesicles. Exosomes, one kind of membrane vesicles containing proteins, mRNA, miRNAs, and DNAs, can be produced by tumor cells as well as other various cell types [5]. Recently, exosomes in tumor microenvironment are attracting more and more attention. They are shown to be small particles but big players in cancer progression and metastasis [6-8] as cancer cells could reprogram surrounding stromal cells into tumor supportive myofibroblasts through secreted exosomes. Data showed that exosomes from ovarian and breast cancer cells can convert adipose-derived MSCs (AMSC) into myofibroblast-like cells [9, 10]. Bonemarrow MSC (BMSC) could also be triggered to differentiate into pro-angiogenic and pro-invasive myofibroblasts by prostate cancer cell-derived exosomes [11]. Exosomes released by chronic lymphocytic leukemia cells could induce the transition of stromal cells into cancer-associated fibroblasts [12].

While most studies concentrate on reprogramming MSCs into tumor-supportive myofibroblasts by various cancer cell-derived exosomes, few studies have paid attention to the immuno-phenotype changes of MSCs after incubation with tumor cells derived exosomes. Tumors are regarded as chronic injuries that are difficult to heal [13], and inflammation plays an important role in tumorigenesis, tumor progression, and metastasis [14]. Besides, MSCs are known for its immunomodulatory capacity through secreting related factors such as cytokines [15]. Thus, there is an urgent need to dictate the immunophenotype changes of MSCs in tumor microenvironment.

Previous research about MSCs immuno-phenotype changes often use pre-conditioned MSCs with inflammatory factors. Results show that long-term stimulation with TNF- $\alpha$, IFN- $\gamma$, and other factors could upregulate the expression of various pro-inflammatory genes in MSCs [16]. The team of Yufang Shi noticed TNFapretreated BM-MSCs mimicked lymphomas-MSCs in their chemokine production profile and ability to promote tumorigenesis of lymphoma, melanoma, and breast carcinoma [17]. Therefore MSCs that have elevated secretion of inflammatory factors show great relevance with tumor progression.

In the present study, we will investigate whether exosomes from lung tumor cells could affect immunophenotype of AMSCs and try to reveal the molecular mechanisms involved in this process. Since few studies have elucidated the mechanisms by which lung cancers influence AMSC through exosomes and lung cancer is one of the leading causes of cancer-related death which incline to transfer to other sites such as bone through tumor-stromal interactions in late stage [18], it is meaningful to explore this question.

\section{Results \\ Lung tumor cell A549-derived exosomes are actively incorporated by MSCs}

Exosomes were isolated from serum-free culture medium of A549 cells through a series of centrifugation and filtration steps. Under transmission electron microscope, these exosomes were observed to be cup-shaped vesicles of approximately $30-120 \mathrm{~nm}$ in diameter (Fig. 1a). In addition, CD63 and HSP70, the protein markers of exosomes, were also detectable (Fig. 1b). Since exosomes could be labeled by lipophilic cell tracking dyes, $\mathrm{DiO}$-labeled exosomes were added to MSCs serum-free culture medium. Exosomes uptake was observed $2 \mathrm{~h}$ after application (Fig. 1c) and accumulated over time (data not shown). These data demonstrate that MSCs can efficiently internalize A549 cell-derived exosomes.

\section{A549 cell-derived exosomes significantly stimulate inflammatory cytokine production in MSCs}

In our previous report about mRNA expression microarray [19], we noticed a remarkable elevation of genes associated with inflammation. Given the important link between inflammation and cancer progression, we began to explore whether A549 exosomes could change inflammatory response in MSCs. MSCs were exposed to $200 \mathrm{ug} / \mathrm{ml} \mathrm{A} 549$ exosomes for $24 \mathrm{~h}$, and the cytokine secretion profile of exosome-treated MSCs were detected by ELISA. Enhanced release of IL-6, IL-8, and MCP-1 was shown (Fig. 2a). To examine whether enhanced release of cytokines in exosome-treated MSCs was timeor concentration-dependent; we treated MSCs with different concentrations of A549 exosomes for 24 and $48 \mathrm{~h}$. As shown in Fig. 2b for cytokine mRNA expression or Fig. 2c for cytokine protein release, no obvious time- or concentration-dependent manner was observed. To further confirm that the enhanced release of these cytokines was caused by exosome, we treated MSCs with exosomedepleted culture medium. As expected, enhanced expression of IL-6, IL-8, and MCP-1 was not observed (Fig. 2d). These data suggest that after exposure to cancer cellderived exosomes, a new kind of pro-inflammatory MSCs (P-MSC) was generated.

\section{P-MSCs promote tumor growth in vivo}

We next determined whether the altered cytokine expression in P-MSCs is accompanied by changes in tumor-promoting capacity in vivo. Using a nude mouse model, we subcutaneously injected A549 cells with PMSCs, MSCs or PBS.As shown in Fig. 3a, the size of tumors significantly increased in the presence of P-MSCs in respect to tumor alone or tumor co-injected with 
A

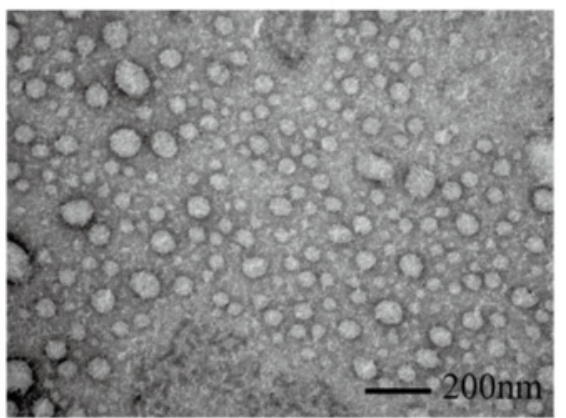

B

Cells Sample1 Sample2
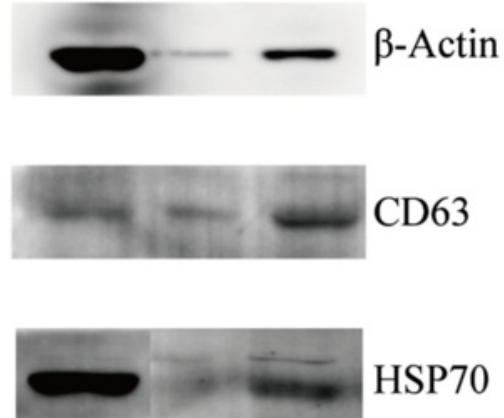

$\mathrm{C}$

\section{Hoechst}
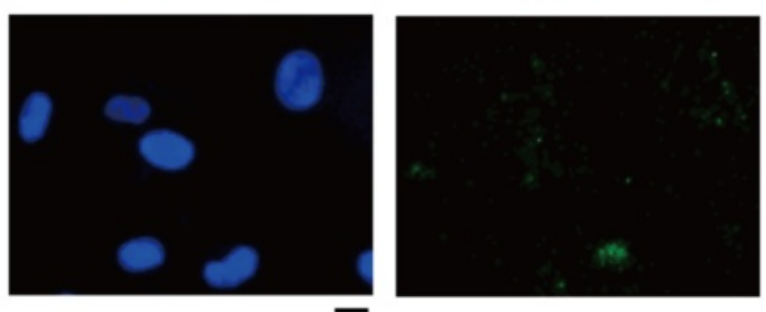

Hoechst/DiO

100um

Fig. 1 Characterization of exosomes secreted by A549 cancer cells. a Electron micrograph of exosomes derived from A549 cancer cells. Scale bar $=200 \mathrm{~nm}$. b Detection of HSP70and CD63 expression in exosomes by Western blot. A549 cells lysate was used as positive control with loading mass of $20 \mu \mathrm{g}$ total proteins. Samples represent A549 exosomes. Sample 1 was 1 mg loaded. Sample 2 was $10 \mu \mathrm{g}$. c Internalization of DiO-labled A549 cancer cells derived exosomes at $2 \mathrm{~h}$ in MSCs. Scale bar $=100 \mathrm{um}$

unstimulated MSCs. Such stimulation in tumor growth was confirmed by measurement of tumor diameter (Fig. 3b). Since MCP-1-mediated macrophage recruitment was relevant with tumor growth and angiogenesis [20], the tumors were excised for examination of immune cell infiltration. We observed that F4/80 macrophages were much more abundant in tumors receiving P-MSCs than those receiving un-stimulated MSCs (Fig. 3c, d). This tumor-promoting effect and the macrophage-recruiting function of P-MSCs corresponded well to their high expression levels of MCP-1 (Fig. 2a), the major macrophage chemokines. In addition, Ki67 staining also showed elevated cell proliferation rate of A549 cells co-administered with PMSCs (Fig. 3e, f). Thus, MSCs educated by A549 exosomes gained an enhanced capacity in recruiting macrophages and in promoting tumor growth in vivo.

\section{NFKB signaling pathway is strikingly activated in P-MSCs}

To further investigate the signaling pathways involved in induction of PMSCs by A549 exosomes, we focused on TLR pathway as it has been reported to be closely related to inflammation. We analyzed gene-expression profiles of MSCs activated by or not by A549 exosomes through the use of a human toll-like receptor signaling pathway PCR array (see the Gene list at Table 1). According to the PCR array analysis (Fig. 4a), inflammation-related pathways including NFkB, JNK, and p38 signaling, were actually activated in P-MSCs. We then investigated the signaling events triggered by exosomes through Western blotting. As shown in Fig. 4b, a rapid activation of $\mathrm{NF}_{\kappa} B$ was detected by phosphorylation of Ikk $\alpha / \beta$ and the p 65 subunit that peaked at $0.5-2 \mathrm{~h}$ after exosome exposure. Rapid activation of JNK, ERK, and p38 signaling was not detected (Fig. 4b). NFKB signaling activation involves phosphorylation of the p65 protein and translocation of the p65 protein to the cell nucleus. Therefore, we determined the localization of p65 in MSCs before and after exposure to A549 exosomes. As expected, A549 exosome stimulation resulted in a significant translocation of p65 from a cytoplasmic to a nuclear localization in Fig. 4c. Moreover, we demonstrated that NFKB inhibitor PDTC remarkably suppressed the enhanced expression of IL-6, IL-8, and MCP1 induced by A549 exosomes in MSCs (Fig. 4d). Together, these results suggest that lung tumor-derived exosomes induce the generation of P-MSCs through activation of NFkB signaling pathway. 


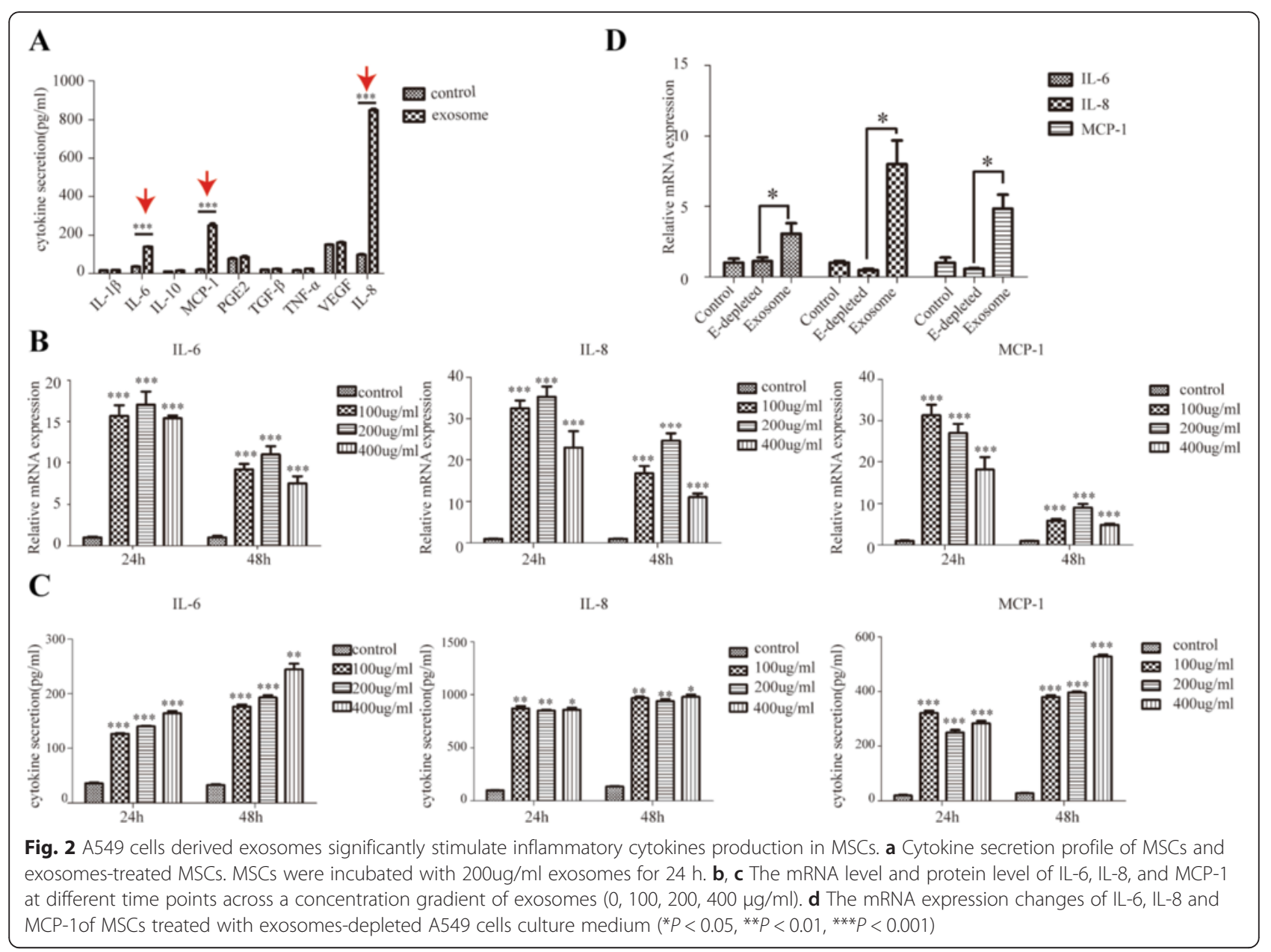

\section{Exosomes trigger cytokine production in MSCs through TLR2}

The effects of exosomes on NFkB prompted us to study more closely the role of TLRs in exosome-mediated signaling. RT-PCR results showed that all TLRs were detectable within 33 cycles in MSCs (Fig. 5a). To determine which TLR was specifically responsible for tumor exosome-mediated cytokine up-regulation in MSCs, we first detected TLRs changes after exosome stimulation. We found that TLR2, TLR7, and TLR8 mRNA expression was significantly increased after exosomes stimulation (Fig. 5b). Here, we focused on TLR2 for three reasons. Firstly, MSCs have higher expression of TLR2 than TLR7 or TLR8 as demonstrated in Fig. 5a, although up-regulation of TLR7 and TLR8 is more significant (Fig. 5b). Secondly, TLR2 is localized on cell plasma membrane whereas TLR7 or TLR8 resides within endosomal compartments. Lastly, TLR2 can recognize lipopeptides while both TLR7 and TLR8 were shown to sense single-stranded viral RNA [21-23]. Using a TLR2 neutralizing antibody, we found that blockade of TLR2 in MSCs decreased the expression of inflammatory factors induced by lung tumor-derived exosomes and inhibited activation of NFKB signaling pathway (Fig. 5c, d).

Furthermore, we knocked down TLR2 with three pairs of designed siRNAs, and we chose siRNA3 as it had the highest interference efficiency of nearly $75 \%$ (Fig. 5e).

SiRNA knockdown of TLR2 also attenuated the expression of IL-6, IL-8 and MCP-1 (Fig. 5f, Additional file 1). Collectively, these data implicated that TLR2 was relevant for exosomes-mediated increase of cytokines IL-6, IL-8, and MCP-1 in MSCs.

\section{Hsp70 on exosomes contribute to cytokine production through TLR2}

To find out whether proteins on exosomes were responsible for PMSCs induction, we treated exosomes with proteinase $\mathrm{K}$ before exposure to MSCs. Interestingly, diminished expression of IL-6, IL-8, andMCP-1 could be observed after treatments with proteinase K (Fig. 6a), suggesting that proteins on exosomes were related with MSCs cytokine production. A variety of molecules have been classified as TLR2 ligands including Versican, HMGB1, and heat shock proteins (HSP). HSP70 is 


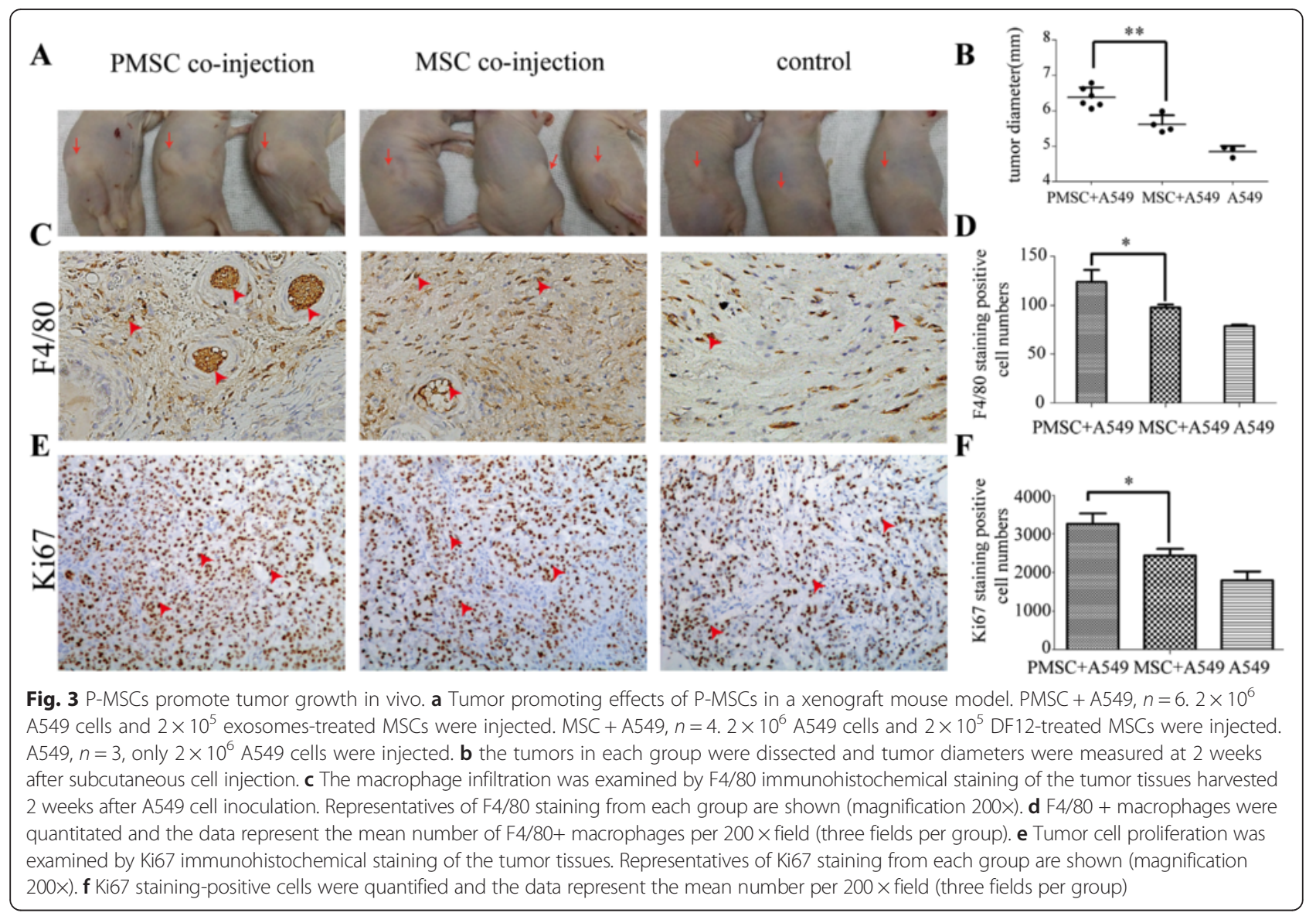

highly expressed on A549 exosomes and it was reported to be a TLR2 ligand [24]. We then evaluated whether A549 exosomes induced generation of P-MSCs through HSP70 or not. Neutralizing antibody of HSP70 could partially suppress the enhanced expression of IL-6, IL-8, and MCP-1 induced by A549 exosomes in MSCs (Fig. 6b). Recombinant human HSP70 (rHSP70) added to MSCs culture mimicked the effect of A549 exosomes in a dose-dependent manner (Fig. 6c). Moreover, interfering TLR2 expression with siRNA could attenuate the effects caused by rHSP70 (Fig. 6d). Altogether, these results indicate that Hsp70 expressed on the surface of exosomes could trigger TLR2 signaling in MSCs.

\section{Discussion}

Exosomes, first considered as "garbage" released from cells, are now exerting starring roles in intercellular communication. Research about exosomes focuses on three areas: disease biomarker in early stage, membrane vesicles as conveyors of immune responses, and roles in cancer [25]. Here, we focus on exosomes in tumor microenvironment. MSCs can be recruited into tumors and form a major component of the tumor microenvironment. Emerging evidence show that tumor cells could modulate MSCs through exosomes including prostate cancer, melanoma, cancer and so on [26, 27]. Although many cancer cells could modulate MSCs into myofibroblasts, the molecular mechanisms involved are not the same. One group reported that the tumorigenic reprogramming of MSCs in prostate cancer was associated with exosomal oncogenic factors such as $\mathrm{H}$-ras and $\mathrm{K}$ ras transcripts, oncomiRNAs, miR-125b etc. [28] Another group suggested that prostate cancer cells could trigger differentiation of fibroblasts into myofibroblasts through exosomal TGF- $\beta$ [26]. Breast cancer-derived exosomes induced the myofibroblastic phenotype and functionality in AMSCs via the SMAD-mediated signaling pathway [10].

Here, we found that MSCs could be educated by lung cancer cell-derived exosomes into pro-inflammatory phenotype and therefore got tumor supportive characteristics. Different from the current research tendency which focuses on the transition from MSCs to myofibroblast caused by tumor cell-derived exosomes, we emphasize on the inflammation phenotype of MSCs. Our results were consistent with previous clinical findings that MSCs require pro-inflammatory cytokines to induce their immunosuppressive function $[29,30]$. This 
Table 1 Gene lists of human toll-like receptor signaling pathway and data for 3D profile

\begin{tabular}{|c|c|c|c|c|c|c|c|c|}
\hline $3 \mathrm{D}$ profile gene data & $A$ & $B$ & C & $D$ & E & $F$ & G & $H$ \\
\hline \multirow[t]{2}{*}{1} & BTK & ECSIT & IKBKB & IRF3 & MYD88 & RELA & TLR3 & ACTB \\
\hline & 0.64 & 0.86 & 0.88 & 0.84 & 1.63 & 1.17 & 1.39 & 1.14 \\
\hline \multirow[t]{2}{*}{2} & CASP8 & EIF2AK2 & IL10 & JUN & NFKB1 & RIPK2 & TLR4 & $\mathrm{B} 2 \mathrm{M}$ \\
\hline & 0.86 & 1.16 & 0.41 & 0.75 & 1.77 & 1.06 & 0.74 & 1.16 \\
\hline \multirow[t]{2}{*}{3} & CCL2 & ELK1 & IL12A & LTA & NFKB2 & SARM1 & TLR5 & GAPDH \\
\hline & 13.80 & 0.85 & 1.35 & 0.91 & 0.41 & 0.81 & 1.71 & 0.87 \\
\hline \multirow[t]{2}{*}{4} & CD14 & FADD & IL $1 \mathrm{~A}$ & LY86 & NFKBIA & SIGIRR & TLR6 & HPRT1 \\
\hline & 1.00 & 0.91 & 0.60 & 0.82 & 3.01 & 1.19 & 0.68 & 1.09 \\
\hline \multirow[t]{2}{*}{5} & CD180 & FOS & IL1B & LY96 & NFKBIL1 & TAB1 & TLR7 & RPLPO \\
\hline & 2.57 & 1.18 & 12.43 & 1.02 & 0.27 & 0.83 & 7.73 & 0.79 \\
\hline \multirow[t]{2}{*}{6} & CD80 & HMGB1 & IL2 & MAP2K3 & NFRKB & TBK1 & TLR8 & \\
\hline & 2.57 & 0.65 & 0.82 & 1.10 & 0.86 & 0.71 & 0.55 & \\
\hline \multirow[t]{2}{*}{7} & CD86 & HRAS & IL6 & MAP2K4 & $\mathrm{NR} 2 \mathrm{C} 2$ & TICAM1 & TLR9 & \\
\hline & 0.82 & 0.27 & 21.55 & 0.95 & 0.85 & 1.58 & 0.71 & \\
\hline \multirow[t]{2}{*}{8} & CHUK & HSP1A1 & IL8 & MAP3K1 & PELT1 & TICAM2 & TNF & \\
\hline & 1.01 & 1.12 & 19.37 & 0.89 & 1.23 & 0.75 & 2.50 & \\
\hline \multirow[t]{2}{*}{9} & CLEC4E & HSPD1 & IRAK1 & MAP3K7 & PPARA & TIRAP & TNFRSF1A & \\
\hline & 0.82 & 0.82 & 0.91 & 0.96 & 0.79 & 0.88 & 1.07 & \\
\hline \multirow[t]{2}{*}{10} & CSF2 & IFNA1 & IRAK2 & MAP4K4 & PRKRA & TLR1 & TOLLIP & \\
\hline & 9.57 & 0.89 & 1.79 & 0.87 & 1.03 & 0.48 & 1.58 & \\
\hline \multirow[t]{2}{*}{11} & CSF3 & IFNB1 & IRAK4 & MAPK8 & PTGS2 & TLR10 & TRAF6 & \\
\hline & 43.95 & 1.42 & 1.58 & 0.86 & 4.75 & 0.30 & 0.91 & \\
\hline \multirow[t]{2}{*}{12} & CXCL10 & IFNG & IRF1 & MAPK8IP3 & REL & TLR2 & UBE2N & \\
\hline & 217.01 & 0.82 & 2.03 & 0.74 & 1.19 & 5.64 & 0.94 & \\
\hline
\end{tabular}

MSCs were treated with or without $200 \mu \mathrm{g} / \mathrm{ml}$ A549 cell-derived exosomes for $24 \mathrm{~h}$. Total RNA were analyzed using human toll-like receptor signaling pathway array. Fold change of RNA expression was used for 3D profile (200-24 h/0-24 h)

indicates the importance of pro-inflammatory MSCs in tumors progression.

However, few studies have elucidated mechanisms about which signal pathways trigger pro-inflammatory phenotype changes in MSCs. Jerome Paggetti reported that exosomes released by chronic lymphocytic leukemia could induce an inflammatory phenotype in stromal cells through activating AKT, ERK1/2, CREB, and GSK3 $\alpha / \beta$ signaling pathways [12]. Several related research explained how tumor cell-derived exosomes cause inflammation in immune cells. Sanchita Bhatnagar et.al found that exosomes released from bacteria-infected macrophages stimulated a pro-inflammatory response in a tolllike receptor-and myeloid differentiation factor 88 (MyD88)-dependent manner [31]. Fanny Chalmin demonstrated that mice tumor-derived exosomal HSP72 induce IL- 6 production by MDSCs through activation of TLR2 and its adaptor MyD88, leading to Stat3 phosphorylation and the promotion of MDSC immunosuppressive functions [32]. Some others thought stress-induced Hsp72 activates macrophages, dendritic cells, and neutrophils by binding to surface bound TLR4 and induce the secretion of pro-inflammatory cytokines [33]. Alexzander Asea et al. [34] also illustrated that HSP70 utilized both TLR2 and TLR4 to transduce its pro-inflammatory signal in a CD14dependent fashion.

These studies suggested the involvement of HSP proteins in exosome-associated inflammation. There remains a question-whether pro-inflammatory properties are unique to cancer-derived exosomes or are an intrinsic feature of all exosomes. We hypothesized that exosomes have a common determinant, HSP70, which is one of the inducers of P-MSCs. However, other protein components of exosomes may also be involved in this process [35]. These determinants need to be further characterized.

In our study, we found that HSP70 on the surface of A549 cell-derived exosomes could activate NF- $\kappa B$ signaling through TLR2 on MSCs. However, TLR2 neutralizing antibody could partially reduce the effects of exosomes, suggesting that TLR4, which also can interact with HSP proteins, may serve as a substitute for TLR2. 
A

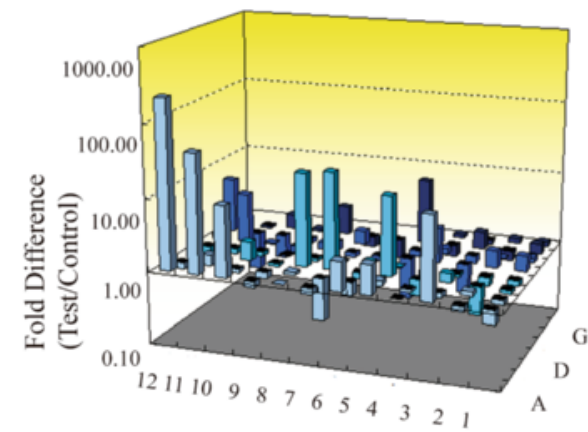

C

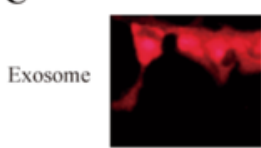

Control

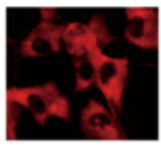

Hoechst

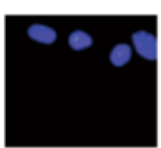

p65/Hoechst
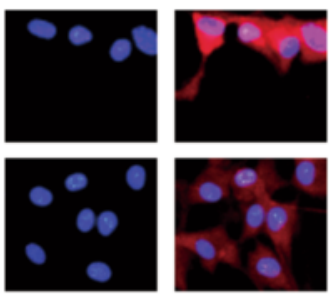

D

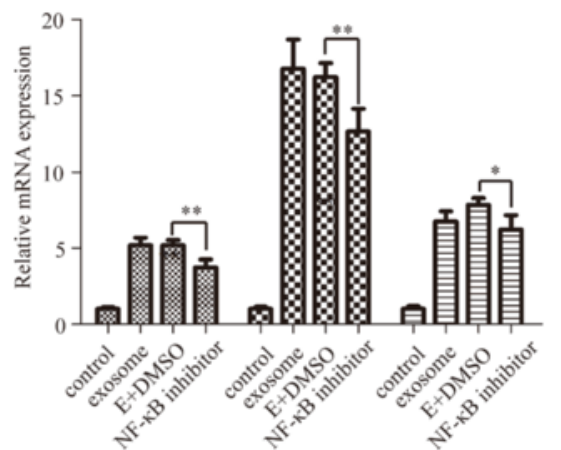

B

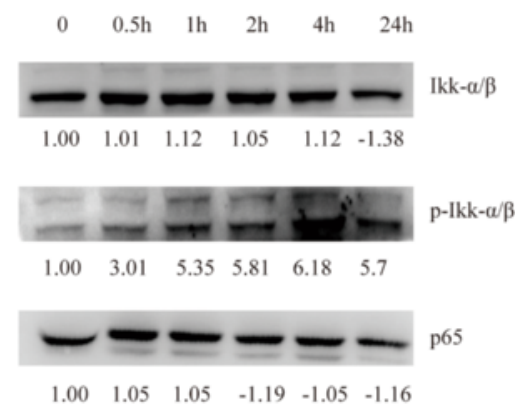

$\begin{array}{llllll}1.00 & 1.05 & 1.05 & -1.19 & -1.05 & -1.16\end{array}$

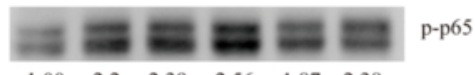

$\begin{array}{llllll}1.00 & 2.2 & 2.39 & 2.56 & 1.87 & 2.38\end{array}$
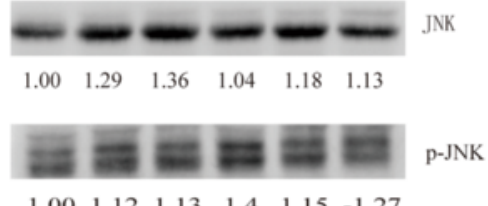

$\begin{array}{lllllll}1.00 & 1.12 & 1.13 & 1.4 & 1.15 & -1.27\end{array}$

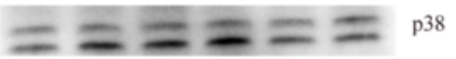

$\begin{array}{llllll}1.00 & 1.11 & 1.08 & 1.49 & 1.20 & -1.11\end{array}$

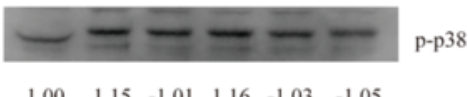

$\mathbf{\infty}$ IL-8

$\begin{array}{lllllll}\mathrm{MCP}-1 & 1.00 & 1.15 & -1.01 & 1.16 & -1.03 & -1.05\end{array}$

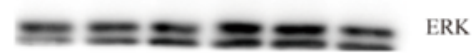

$\begin{array}{llllll}1.00 & 2.66 & 4.54 & 2.96 & 3.70 & 2.65\end{array}$

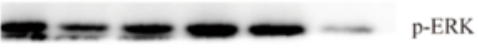

$\begin{array}{llllll}1.00 & -1.47 & 1.06 & -1.21 & -1.05 & -6.34\end{array}$

GAPDH

$\begin{array}{llllll}1.00 & 1.00 & 1.00 & 1.00 & 1.00 & 1.00\end{array}$

Fig. 4 NFKB signaling pathway is strikingly activated in P-MSCs. a 3D profile of RT ${ }^{2}$ Profiler' ${ }^{T M}$ PCR Array of Human Toll-Like Receptor Signaling Pathway. b Activation of NF-KB in P-MSC was determined by Western blotting. The fold difference in band intensities was quantified and indicated under the image using the software of AlphaView. c Representative pictures of cellular immunofluorescence staining for nuclear p65 in MSCs or P-MSC at $2 \mathrm{~h}$. Immunocytochemistry staining was performed using an anti-p65 antibody (red) and Hoechst (blue) for nuclear staining. $\mathbf{d}$ Relative mRNA expression of IL-6, IL-8, and MCP-1. MSCs were pre-treatment with or without the NF-KB inhibitor (PDTC, $10 \mu \mathrm{M})$ at $37^{\circ} \mathrm{C}$ for $1 \mathrm{~h}$ and then incubated with $200 \mathrm{\mu g} / \mathrm{ml}$ A549 cell-derived exosomes at $37^{\circ} \mathrm{C}$ for $24 \mathrm{~h}\left({ }^{*} P<0.05,{ }^{* *} P<0.01,{ }^{* * *} P<0.001\right)$

Additionally, we should consider the role of RNA component in exosomes in our future study. We noticed the decreased expression of inflammatory factors after pre-treating exosomes with Rnase A (data not shown), which implied the involvement of exosomal RNAs. It has been shown that acute stressor exposure modified plasma exosome-associated Hsp72 and microRNA (miR142-5p and miR-203) [36]. Exosomal miRNAs can affect cells of the tumor microenvironment [37] both in a canonical (mRNA-targeting) and non-canonical (receptorbinding) manner. Tumor exosomal miR-21 and miR-29a can function by binding as ligands to receptors of the TLR family in immune cells, triggering a TLR-mediated prometastatic inflammatory response that ultimately leads to tumor growth and metastasis [38].

Considerable evidence suggests that pro-inflammatory pathways drive self-renewal of cancer stem-like cells. HSPs are key players during inflammation besides their chaperone and cytoprotective functions. Interest in HSP70 inhibitors is increasing as potential anticancer agents in recent years $[39,40]$. By reprogramming proinflammatory MSCs in tumor microenvironment using 


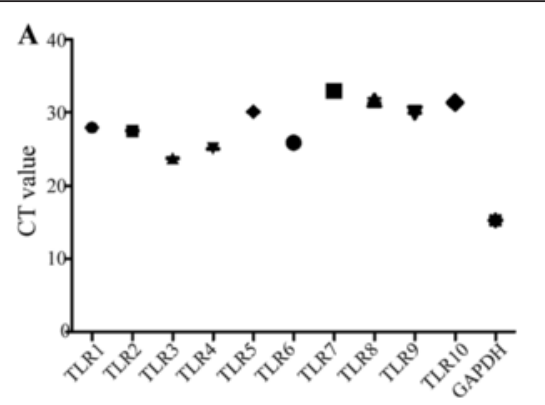

B
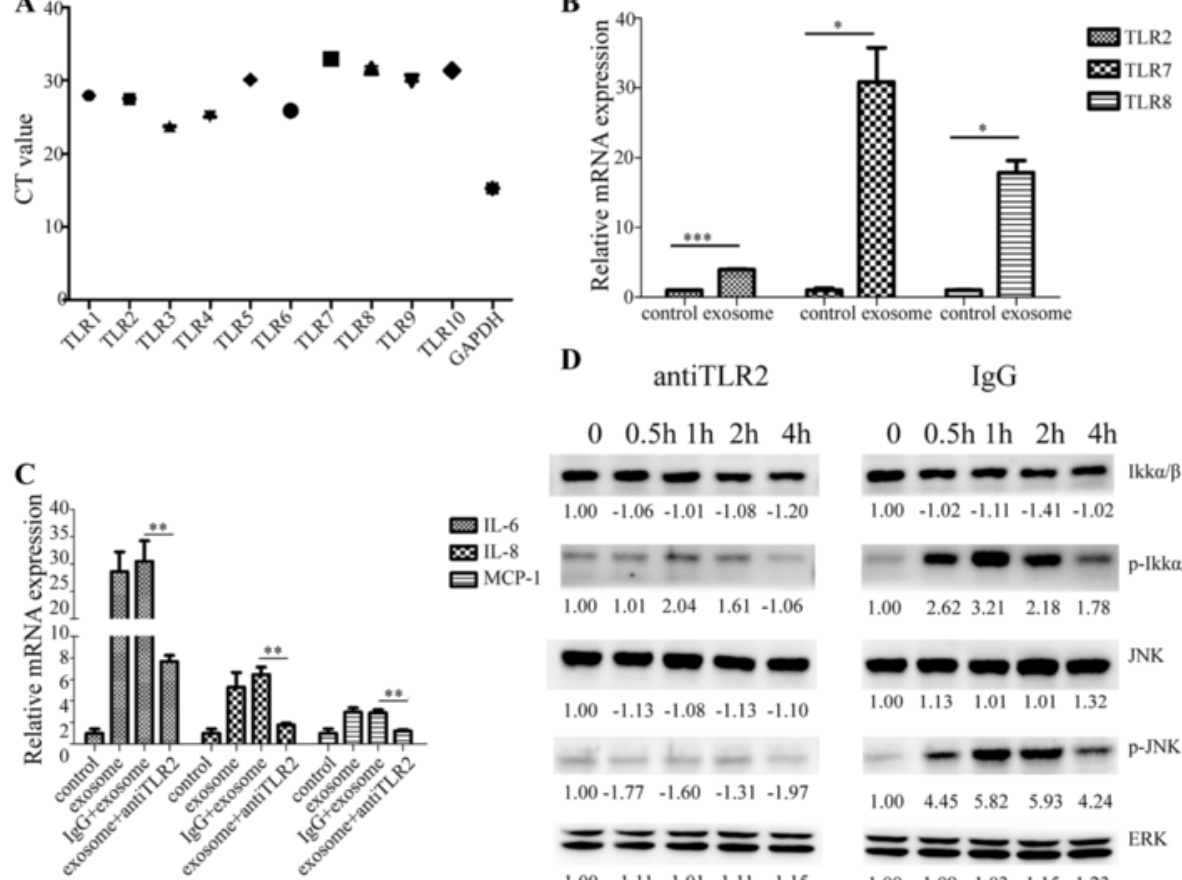

$0 \quad 0.5 \mathrm{~h} 1 \mathrm{~h} \quad 2 \mathrm{~h} \quad 4 \mathrm{~h}$

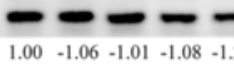

这L-8
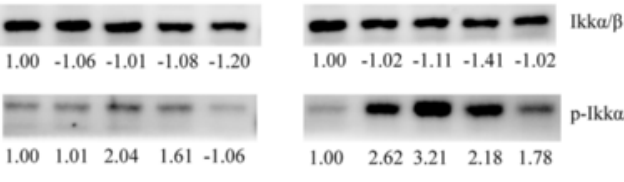

$1.00-1.02-1.11-1.41-1.02$

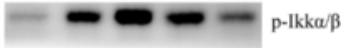

$\begin{array}{lllll}1.00 & 2.62 & 3.21 & 2.18 & 1.78\end{array}$

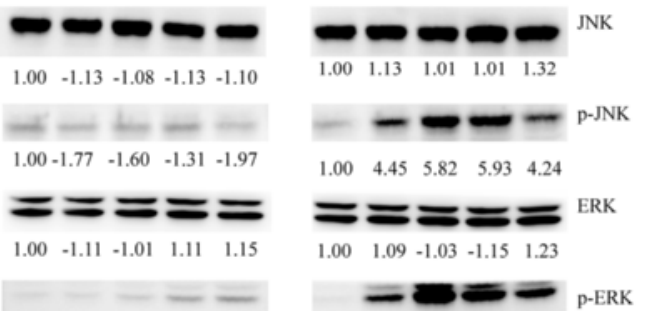

$\begin{array}{lllll}1.00 & 1.09 & 2.04 & 4.35 & 5.59\end{array}$

1.0037 .2177 .8657 .3855 .66

E

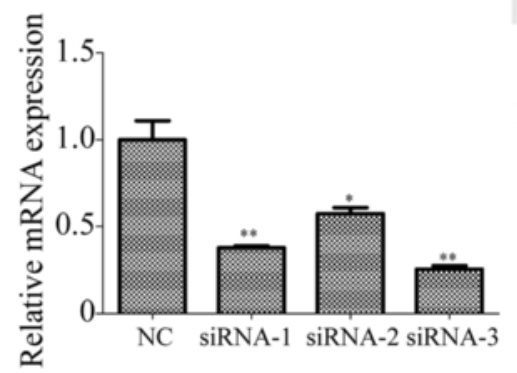

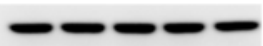

$\begin{array}{lllll}1.00 & 1.00 & 1.00 & 1.00 & 1.00\end{array}$

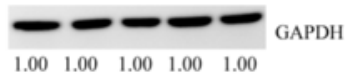

F

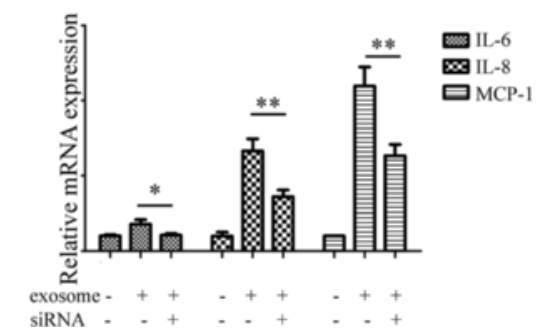

Fig. 5 Exosomes trigger cytokine production in MSCs through TLR2. a The expression level of TLR $1 \sim 10$ of MSCs. GAPDH was used as control. b mRNA expression changes of TLR2, 7, 8 were detected by RT-PCR after treatment with exosomes. c mRNA expression changes of IL-6, IL-8, and MCP-1 of MSCs. MSCs were pre-treated withTLR2 neutralizing antibody or mouse lgG2b isotype control at $37^{\circ} \mathrm{C}$ for $1 \mathrm{~h}$ and then incubated with exosomes for $24 \mathrm{~h}$. $\mathbf{d}$ Western blotting analysis of NF-KB activation in P-MSCs. MSCs treated with mouse lgG2b isotype control was used as control. e The interfering efficiency of three pairs of TLR2 siRNAs was measured by RT-PCR. $\mathbf{f}$ mRNA expression changes of IL-6, IL-8, and MCP-1. MSCs were stimulated with exosomes after knockdown of TLR2 by siRNA for $24 \mathrm{~h}\left({ }^{*} P<0.05,{ }^{* *} P<0.01,{ }^{* *} P<0.001\right)$

HSP70 inhibitors, tumor progression may be controlled. But there is still a lot of "dark matter" to reveal before the welcome of light for cancer patients.

\section{Conclusions}

This study demonstrates that lung cancer cell-derived exosomes could educate naïve MSCs into a new kind of pro-inflammatory MSCs (P-MSCs) by activating TLR2/ NF- $\mathrm{kB}$ signaling through exosomal surface HSP70. Importantly, this new kind of P-MSCs could support tumor growth (Fig. 7).

\section{Methods}

\section{Exosome isolation}

Exosome extraction was performed as previously described [41]. Briefly, A549 cells were cultured in serumfree DF12 medium for $24 \mathrm{~h}$. Then, the culture medium was collected and centrifuged at $800 \mathrm{~g}$ for $5 \mathrm{~min}$ and additional $2000 \mathrm{~g}$ for $10 \mathrm{~min}$ to remove lifted cells. The supernatant was subjected to filtration on a $0.1-\mathrm{mm}$ pore polyethersulfone membrane filter (Corning) to remove cell debris and large vesicles, followed by concentration by a $100,000 \mathrm{Mw}$ cutoff membrane (CentriPlus-70, Millipore). The volume of supernatant was reduced from 


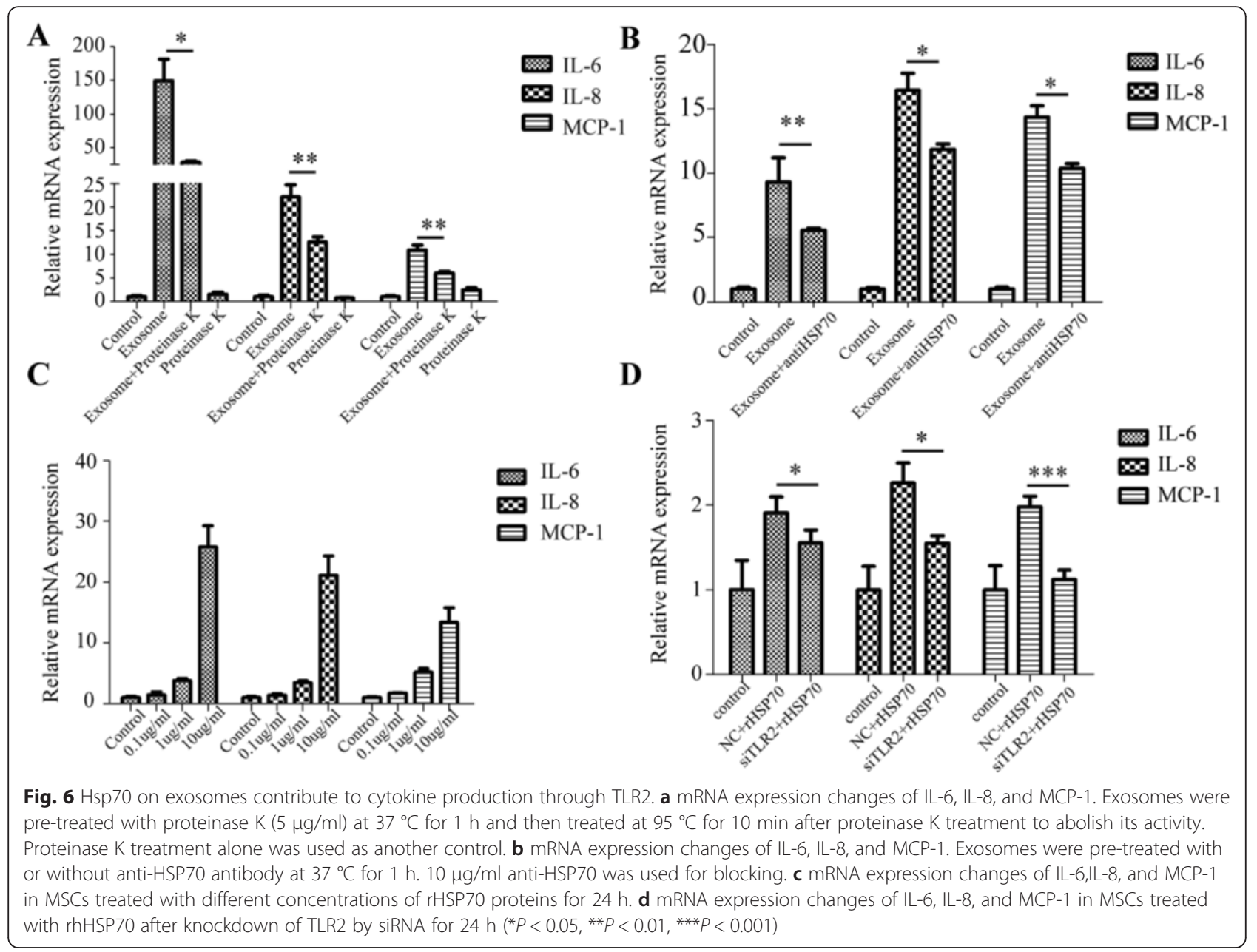

approximately $250-500 \mathrm{~mL}$ to less than $5 \mathrm{~mL}$. The supernatant was then ultracentrifuged at $100,000 \mathrm{~g}$ for $1 \mathrm{~h}$ at $4{ }^{\circ} \mathrm{C}$ using $70 \mathrm{Ti}$ rotor (Beckman Coulter). The resulting pellets were resuspended in $6 \mathrm{~mL}$ PBS and ultracentrifuged at $100,000 \mathrm{~g}$ for $1 \mathrm{~h}$ at $4{ }^{\circ} \mathrm{C}$ using 100Ti rotor (Beckman Coulter).

\section{Transmission electron microscopy}

Purified exosomes were fixed with $1 \%$ glutaraldehyde in PBS (pH 7.4). After rinsing, a 20-uL drop of the suspension was loaded onto a formvar/carbon-coated grid, negatively stained with $3 \%(\mathrm{w} / \mathrm{v})$ aqueous phosphotungstic acid for $1 \mathrm{~min}$, and observed by transmission electron microscope.

\section{Isolation and culture of MSCs from adipose tissue}

Human adipose tissue was obtained from liposuction aspirates with informed consent of the donors and was performed according to procedures provided by the Ethics Committee at the Chinese Academy of Medical Sciences and Peking Union Medical College. The isolation and culture procedures were described as previously reported [42]. hAMSCs were resuspended in $12 \mathrm{ml}$ culture medium and seeded at a density of $2 \times 10^{6}$ cells in a $75-\mathrm{cm}^{2}$ culture flask. Cell cultures were maintained at $37{ }^{\circ} \mathrm{C}$ in a humidified incubator with $5 \% \mathrm{CO}_{2}$ and passaged with trypsin/EDTA when cells were confluent. Passage 3 cells were used for following experiments.

\section{Quantitative real-time polymerase chain reaction}

Cultured cells were lysed by TRIzol (Invitrogen, USA), and RNA was extracted according to the manufacturer's instruction. One microgram of total RNA from each sample was reverse transcribed using M-MLV (Takara) in a final volume of $20 \mathrm{uL}$. The polymerase chain reaction (PCR) amplification was carried out using the Step-one System (Bio-Rad) with SYBR Green Mastermix (Takara). All quantitative real-time PCR (qRT-PCR) results were carried out in duplicate and normalized to GAPDH. The primer of the related gene list is found in Table 2.

\section{Western blotting}

After washing twice with cold PBS, cells were lysed in RIPA lysis buffer (Beyotime, Shanghai, China) with 


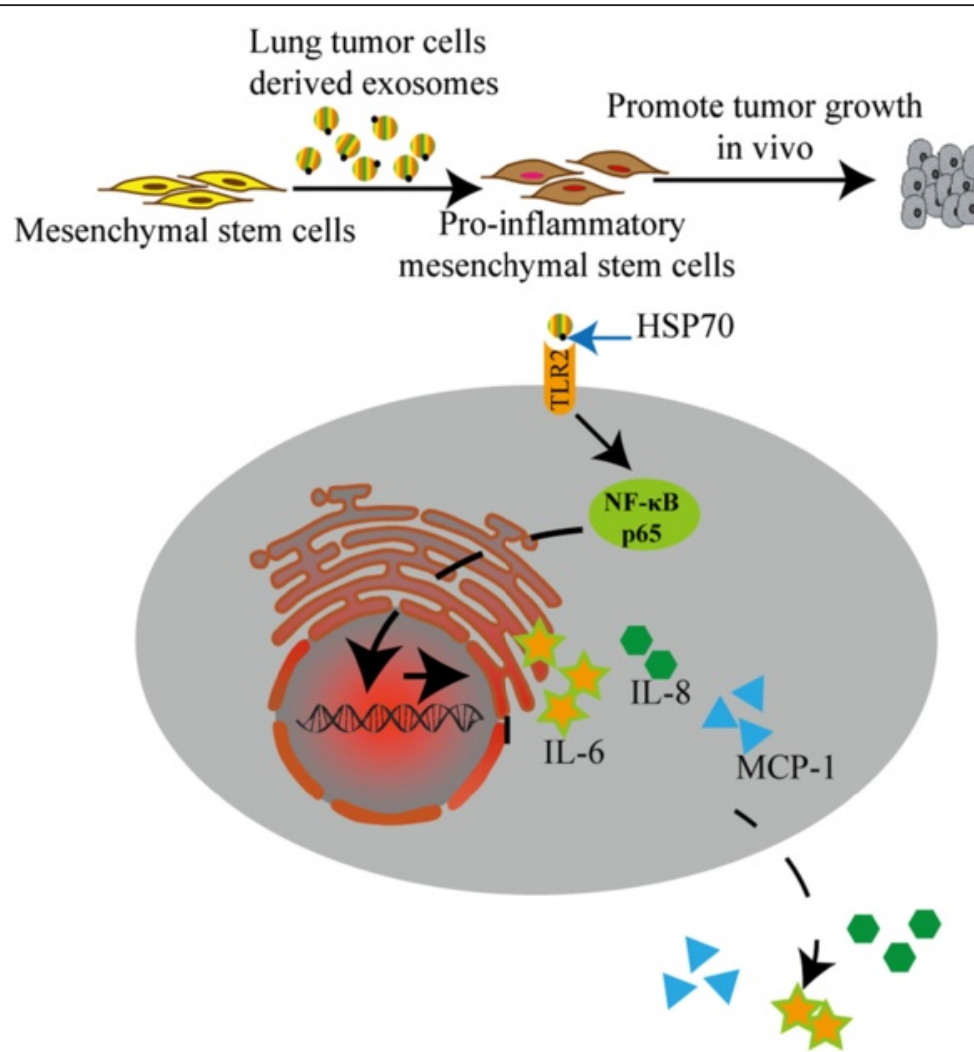

Fig. 7 A schematic illustration showed that lung tumor cell-derived exosomes could educate naïve MSCs into a new kind of pro-inflammatory MSCs (P-MSCS) by activating TLR2/NF-KB signaling through exosomal surface HSP70

$1 \mathrm{mM}$ PMSF and protease inhibitor cocktail on ice for $30 \mathrm{~min}$, manually scraped from culture plates and then quantified using the BCA Protein Assay Kit (Beyotime). Proteins were separated on $10 \%$ sodium dodecyl sulfatepolyacrylamide gel electrophoresis (SDS-PAGE) gels, electroblotted onto a polyvinylidene difluoride (PVDF) membrane $(0.22 \mu \mathrm{m}$, Millipore, Billerica, MA, USA). The membranes were blocked with $5 \%$ BSA and incubated with specific antibodies overnight at $4{ }^{\circ} \mathrm{C}$ and then were incubated with horseradish peroxidase (HRP)-conjugated secondary antibody for $1 \mathrm{~h}$ at room temperature. The primary antibodies were as follows: IKK $\alpha / \beta$, phosphorus $\mathrm{IKK} \alpha / \beta$, p65, phosphorus p65, JNK, phosphorus JNK, phosphorus p38 (1/1000, Cell Signaling Technology, USA), CD63, HSP70 (1/1000, Abcam), GAPDH (1/1000, Santa cruz), and $\beta$-actin (1/1000, Zhongshan, Beijing China). Secondary (HRP)-conjugated antibodies were purchased from NeoBioscience. Antibody and antigen complexes were detected using chemiluminescent ECL reagent (Millipore, USA).

\section{siRNA transfection}

Three pairs of siRNA of TLR2 were designed and synthesized (Gene Pharma, Inc., Shanghai, China). The synthetics were transfected into AMSCs at the final concentration of $200 \mathrm{nM}$ using lipofectamine 2000 (Invitrogen, USA) according to the manufacturer's instructions. The whole transfection process was proceeded in a non-serum medium named opti-mem (Gibco, USA) for $6 \mathrm{~h}$ at $37^{\circ} \mathrm{C}$ in a humidified environment containing $5 \% \mathrm{CO} 2$. After transfection, the medium was changed into DF12 medium with or without cancer exosomes.

\section{Cytokine analysis}

Culture supernatants were collected after treatment with or without exosomes for $24 \mathrm{~h}$. The concentrations of all cell cytokines in supernatants were measured using ELISA kits (BD Technologies).

\section{Immunofluorescence staining}

The cultured cells were fixed at $4{ }^{\circ} \mathrm{C}$ in ice-cold methanol for $10 \mathrm{~min}$, washed three times in phosphatebuffered saline (PBS), and then permeabilized in $0.1 \%$ Triton X-100/PBS for $10 \mathrm{~min}$ at room temperature. Nonspecific binding was blocked with $0.5 \%$ Tween-20/ PBS containing $1 \%$ bovine serum albumin (BSA) for $30 \mathrm{~min}$. The primary antibodies were incubated at $4{ }^{\circ} \mathrm{C}$ overnight. The secondary antibodies incubated for $1 \mathrm{~h}$ at 
Table 2 Primers for RT-PCR

\begin{tabular}{|c|c|}
\hline Gene & Forward primer and reverse primer $\left(5^{\prime}-3^{\prime}\right)$ \\
\hline$A L P$ & CCACGTCTTCACATTTGGTG; AGACTGCGCCTGGTAGTTGT \\
\hline$R \cup N X 2$ & TGTCATGGCGGGTAACGAT; AAGACGGTTATGGTCAAGGTGAA \\
\hline OCN & GGCGCTACCTGTATCAATGG; GTGGTCAGCCAACTCGTCA \\
\hline PPAR Y & CCTATTGACCCAGAAAGCGATT; CATTACGGAGAGATCCACGGA \\
\hline$L P L$ & ACAAGAGAGAACCAGACTCCAA; AGGGTAGTTAAACTCCTCCTCC \\
\hline$C / E B P \beta$ & CTTCAGCCCGTACCTGGAG; GGAGAGGAAGTCGTGGTGC \\
\hline IL-6 & ACTCACCTCTTCAGAACGAATTG;CCATCTTTGGAAGGTTCAGGTTG \\
\hline IL-8 & ACTCCAAACCTTTCCACCCC; TTCTCAGCCCTCTTCAAAAACTTC \\
\hline MCP-1 & CAGCCAGATGCAATCAATGCC; TGGAATCCTGAACCCACTTCT \\
\hline $\mid L-1 \beta$ & AGCTACGAATCTCCGACCAC; CGTTATCCCATGTGTCGAAGAA \\
\hline TNF- $a$ & ССTCTCTCTAATCAGCCCTCTG; GAGGACCTGGGAGTAGATGAG \\
\hline IFN- $a$ & GCCTCGCCCTTTGCTITACT; CTGTGGGTCTCAGGGAGATCA \\
\hline IFN- $\beta$ & GCTTGGATTCCTACAAAGAAGCA;ATAGATGGTCAATGCGGCGTC \\
\hline IFN- $-\gamma$ & TCGGTAACTGACTTGAATGTCCA; TCGCTTCCCTGTITTAGCTGC \\
\hline CTA2 & CGATGCTCCCAGGGCTGTTT; TTCGTCACCCACGTAGCTGTCTIT \\
\hline TLR1 & CCACGTTCCTAAAGACCTATCCC; CCAAGTGCTTGAGGTTCACAG \\
\hline TLR2 & ATCCTCCAATCAGGCTTCTCT; GGACAGGTCAAGGCTITTIACA \\
\hline TLR3 & TTGCCTTGTATCTACTTITGGG; TCAACACTGTTATGTITGTGGGT \\
\hline TLR4 & AGACCTGTCCCTGAACCCTAT; CGATGGACTTCTAAACCAGCCA \\
\hline TLR5 & TCCCTGAACTCACGAGTCTTT; GGTTGTCAAGTCCGTAAAATGC \\
\hline TLR6 & TGAATGCAAAAACCCTTCACC; CCAAGTCGTTTCTATGTGGTTGA \\
\hline TLR7 & CACATACCAGACATCTCCCC; CCCAGTGGAATAGGTACACAGTT \\
\hline TLR8 & ATGTTCCTTCAGTCGTCAATGC; TTGCTGCACTCTGCAATAACT \\
\hline TLR9 & CTGCCACATGACCATCGAG; GGACAGGGATATGAGGGATTTGG \\
\hline TLR10 & GGTTCTITTGCGTGATGGAATC; GTCGTCCCAGAGTAAATCAAC \\
\hline GAPDH & GGTCACCAGGGCTGCTTITA; GGATCTCGCTCCTGGAAGATG \\
\hline
\end{tabular}

room temperature. The incubated cells were washed in PBS, and Hoechst 33342 (Sigma-Aldrich) was used to visualize nuclei. p65 antibody (10745-1-AP) was purchased from Proteintech.

\section{Animal experiments}

All nude mice were purchased from the Laboratory Animal Center of the Chinese Academy of Medical Sciences (Beijing, China). All mice were bred and maintained under specific pathogen-free conditions. Animal use and experimental procedures were approved by the Animal Care and Use Committee of the Chinese Academy of Medical Sciences. All nude mice received a subcutaneous injection of $2 \times 10^{6}$ A549 cells. One group received a subcutaneous injection of $2 \times 10^{5}$ PMSCs. The other group received a subcutaneous injection of $2 \times 10^{5}$ MSCs. The last group only received an injection of A549 cells. The tumor volume was measured after 2 weeks. The tumor tissues were fixed with $10 \%$ PFA and the peripheral blood were collected for C-flow analysis. Each group was treated with $\mathrm{HE}, \mathrm{Ki} 67$, and F4/80 staining. Ki67 antibody was purchased from Proteintech (199721-AP). F4/80 antibody was purchased from Abcam (ab6640).

\section{Statistical analysis}

Data are presented as mean $\pm \mathrm{SD}$. Comparisons between groups were analyzed via Student's $t$ test. Differences were considered statistically significant at ${ }^{*} P<0.05$, ** $P<0.01$, and ***P $P<0.001$.

\section{Additional file}

Additional file 1: mRNA expression changes of $I L-6, I L-8$ and MCP-1 in MSCs stimulated with exosomes after knockdown of TLR2 by siRNA combinations for $24 \mathrm{~h}$. (TIF $236 \mathrm{~kb}$ )

\begin{abstract}
Abbreviations
ALP: alkaline phosphatase; AMSCs: adipose tissue-derived MSCs;

BMSCs: bone-marrow-derived MSCs; EDTA: ethylene diamine tetra-acetic acid; ELISA: enzyme-linked immunosorbent assay; FBS: fetal bovine serum; FITC: fluorescein isothiocyanate; H-DMEM: high glucose of Dulbecco's modified Eagle's medium; HE: hematoxylin-eosin; HSP: heat shock protein; IL: interleukin; JNK: c-Jun N-terminal kinase; MCP-1: monocyte chemotactic protein 1; MSCs: mesenchymal stem cells; MyD88: myeloid differentiation factor 88; NF-kB: nuclear factor kappa-light-chain-enhancer of activated B cells; PAMP: pathogen associated molecular pattern; PBS: phosphate buffered saline; PCR: polymerase chain reaction; P-MSC: pro-inflammatory MSCs; qRTPCR: quantitative real-time PCR; RT-PCR: reverse transcription polymerase chain reaction; TGF- $\beta 1$ : transforming growth factor beta 1 ; TLR: toll-like receptor.
\end{abstract}

\section{Competing interests}

All authors declare that they have no competing interests.

\section{Authors' contributions}

$\mathrm{XL}$ performed and analyzed the experiments and wrote the manuscript. SW designed and analyzed the experiments and critically revised the drafting of the manuscript. RZ and $H \mathrm{~L}$ analyzed the data and provided helpful suggestions in the drafting of the manuscript. $\mathrm{QH}$ performed the cell immunofluorescence staining and helped design the experiment. RCZ designed the experiment. All authors have read and approved the final manuscript.

\section{Acknowledgements}

This study was supported by grants from the National Natural Science Foundation of China (No. 81370466), the National Science and Technology Major Projects for "Drug Research and Development" (2014ZX09101042), Key Program for Beijing Municipal Natural Science Foundation (No.7141006), National Collaborative Innovation Program (for Biotherapy), Beijing Science and Technology Project (Z151100001615063).

Received: 29 January 2016 Accepted: 11 April 2016

Published online: 18 April 2016

References

1. Rowley DR. Reprogramming the tumor stroma: a new paradigm. Cancer Cell. 2014;26(4):451-2.

2. Turley SJ, Cremasco V, Astarita JL. Immunological hallmarks of stromal cells in the tumour microenvironment. Nat Rev Immunol. 2015;15(1 1):669-82.

3. Pittenger MF, Mackay AM, Beck SC, Jaiswal RK, Douglas R, Mosca JD, Moorman MA, Simonetti DW, Craig S, Marshak DR. Multilineage potential of adult human mesenchymal stem cells. Science. 1999;284(5411):143-7.

4. Sun Z, Wang S, Zhao RC. The roles of mesenchymal stem cells in tumor inflammatory microenvironment. J Hematol Oncol. 2014;7:14. 
5. Keller S, Sanderson MP, Stoeck A, Altevogt P. Exosomes: from biogenesis and secretion to biological function. Immunol Lett. 2006;107(2):102-8.

6. Azmi AS, Bao B, Sarkar FH. Exosomes in cancer development, metastasis, and drug resistance: a comprehensive review. Cancer Metastasis Rev. 2013; 32(3-4):623-42.

7. Kahlert C, Kalluri R. Exosomes in tumor microenvironment influence cancer progression and metastasis. J Mol Med (Berl). 2013;91(4):431-7.

8. Zhang X, Yuan X, Shi H, Wu L, Qian H, Xu W. Exosomes in cancer: small particle, big player. J Hematol Oncol. 2015;8(1):83.

9. Cho JA, Park H, Lim EH, Kim KH, Choi JS, Lee JH, Shin JW, Lee KW. Exosomes from ovarian cancer cells induce adipose tissue-derived mesenchymal stem cells to acquire the physical and functional characteristics of tumorsupporting myofibroblasts. Gynecol Oncol. 2011;123(2):379-86.

10. Lee K. Exosomes from breast cancer cells can convert adipose tissuederived mesenchymal stem cells into myofibroblast-like cells. Int J Oncol. 2012;40(1):130-138.

11. Chandler EM, Seo BR, Califano JP, Andresen Eguiluz RC, Lee JS, Yoon CJ, Tims DT, Wang JX, Cheng L, Mohanan S, Buckley MR, Cohen I, Nikitin AY, Williams RM, Gourdon D, Reinhart-King CA, Fischbach C. Implanted adipose progenitor cells as physicochemical regulators of breast cancer. Proc Natl Acad Sci U S A. 2012;109(25):9786-91.

12. Paggetti J, Haderk F, Seiffert M, Janji B, Distler U, Ammerlaan W, Kim YJ, Adam J, Lichter P, Solary E, Berchem G, Moussay E. Exosomes released by chronic lymphocytic leukemia cells induce the transition of stromal cells into cancer-associated fibroblasts. Blood. 2015;126(9):1106-17.

13. Riss J, Khanna C, Koo S, Chandramouli GV, Yang HH, Hu Y, Kleiner DE, Rosenwald A, Schaefer CF, Ben-Sasson SA, Yang L, Powell J, Kane DW, Star RA, Aprelikova O, Bauer K, Vasselli JR, Maranchie JK, Kohn KW, Buetow KH, Linehan WM, Weinstein JN, Lee MP, Klausner RD, Barrett JC. Cancers as wounds that do not heal: differences and similarities between renal regeneration/repair and renal cell carcinoma. Cancer Res. 2006;66(14):7216-24.

14. Whiteside TL. The tumor microenvironment and its role in promoting tumor growth. Oncogene. 2008;27(45):5904-12.

15. Wang $Y$, Chen $X$, Cao W, Shi $Y$. Plasticity of mesenchymal stem cells in immunomodulation: pathological and therapeutic implications. Nat Immunol. 2014;15(11):1009-16.

16. Wang L, Zhao Y, Liu Y, Akiyama K, Chen C, Qu C, Jin Y, Shi S. IFN-gamma and TNF-alpha synergistically induce mesenchymal stem cell impairment and tumorigenesis via NFkappaB signaling. Stem Cells. 2013;31(7):1383-95.

17. Ren G, Zhao X, Wang $Y$, Zhang $X$, Chen $X$, Xu C, Yuan ZR, Roberts Al, Zhang $L$, Zheng B, Wen T, Han Y, Rabson AB, Tischfield JA, Shao C, Shi Y. CCR2dependent recruitment of macrophages by tumor-educated mesenchyma stromal cells promotes tumor development and is mimicked by TNFalpha. Cell Stem Cell. 2012;11(6):812-24.

18. Esposito M, Kang Y. Targeting tumor-stromal interactions in bone metastasis. Pharmacol Ther. 2014;141(2):222-33.

19. Wang S, Li X, Zhu R, Han Q, Zhao RC. Lung cancer exosomes initiate global long non-coding RNA changes in mesenchymal stem cells. Int J Oncol. 2016:48(2):681-689.

20. Arendt LM, McCready J, Keller PJ, Baker DD, Naber SP, Seewaldt V, Kuperwasser C. Obesity promotes breast cancer by CCL2-mediated macrophage recruitment and angiogenesis. Cancer Res. 2013;73(19):6080-93.

21. Heil F, Hemmi H, Hochrein H, Ampenberger F, Kirschning C, Akira S, Lipford $\mathrm{G}$, Wagner $\mathrm{H}$, Bauer S. Species-specific recognition of single-stranded RNA via toll-like receptor 7 and 8. Science. 2004;303(5663):1526-9.

22. Jin MS, Kim SE, Heo JY, Lee ME, Kim HM, Paik SG, Lee H, Lee JO. Crystal structure of the TLR1-TLR2 heterodimer induced by binding of a tri-acylated lipopeptide. Cell. 2007;130(6):1071-82

23. Kang JY, Nan X, Jin MS, Youn SJ, Ryu YH, Mah S, Han SH, Lee H, Paik SG, Lee JO. Recognition of lipopeptide patterns by Toll-like receptor 2-Toll-like receptor 6 heterodimer. Immunity. 2009;31(6):873-84.

24. Mathur S, Walley KR, Wang Y, Indrambarya T, Boyd JH. Extracellular heat shock protein 70 induces cardiomyocyte inflammation and contractile dysfunction via TLR2. Circ J. 2011;75(10):2445-52.

25. Lou G, Song X, Yang F, Wu S, Wang J, Chen Z, Liu Y. Exosomes derived from miR-122-modified adipose tissue-derived MSCs increase chemosensitivity of hepatocellular carcinoma. J Hematol Oncol. 2015;8(1):122.

26. Chowdhury R, Webber JP, Gurney M, Mason MD, Tabi Z, Clayton A. Cancer exosomes trigger mesenchymal stem cell differentiation into proangiogenic and pro-invasive myofibroblasts. Oncotarget. 2015;6(2):715-31.
27. Peinado H, Aleckovic M, Lavotshkin S, Matei I, Costa-Silva B, Moreno-Bueno G, Herqueta-Redondo M, Williams C, Garcia-Santos G, Ghajar C, Nitadori-Hoshino A, Hoffman C, Badal K, Garcia BA, Callahan MK, Yuan J, Martins VR, Skog J, Kaplan RN, Brady MS, Wolchok JD, Chapman PB, Kang Y, Bromberg J, Lyden D. Melanoma exosomes educate bone marrow progenitor cells toward a prometastatic phenotype through MET. Nat Med. 2012;18(6):883-91.

28. Abd Elmageed ZY, Yang Y, Thomas R, Ranjan M, Mondal D, Moroz K, Fang Z, Rezk BM, Moparty K, Sikka SC, Sartor O, Abdel-Mageed AB. Neoplastic reprogramming of patient-derived adipose stem cells by prostate cancer cell-associated exosomes. Stem Cells. 2014;32(4):983-97.

29. Wang D, Li J, Zhang Y, Zhang M, Chen J, Li X, Hu X, Jiang S, Shi S, Sun L. Umbilical cord mesenchymal stem cell transplantation in active and refractory systemic lupus erythematosus: a multicenter clinical study. Arthritis Res Ther. 2014;16(2):R79.

30. Liew A, O'Brien T, Egan L. Mesenchymal stromal cell therapy for Crohn's disease. Dig Dis. 2014;32 Suppl 1:50-60.

31. Bhatnagar S, Shinagawa K, Castellino FJ, Schorey JS. Exosomes released from macrophages infected with intracellular pathogens stimulate a proinflammatory response in vitro and in vivo. Blood. 2007;110(9):3234-44.

32. Chalmin F, Ladoire S, Mignot G, Vincent J, Bruchard M, Remy-Martin JP, Boireau W, Rouleau A, Simon B, Lanneau D, De Thonel A, Multhoff G, Hamman A, Martin F, Chauffert B, Solary E, Zitvogel L, Garrido C, Ryffel B, Borg C, Apetoh L, Rebe C, Ghiringhelli F. Membrane-associated Hsp72 from tumor-derived exosomes mediates STAT3-dependent immunosuppressive function of mouse and human myeloid-derived suppressor cells. J Clin Invest 2010;120(2):457-71.

33. Campisi J, Fleshner M. Role of extracellular HSP72 in acute stress-induced potentiation of innate immunity in active rats. J Appl Physiol (1985). 2003;94(1):43-52.

34. Asea A, Rehli M, Kabingu E, Boch JA, Bare O, Auron PE, Stevenson MA, Calderwood SK. Novel signal transduction pathway utilized by extracellular HSP70: role of toll-like receptor (TLR) 2 and TLR4. J Biol Chem. 2002;277(17): 15028-34.

35. Liu S, Xiong X, Zhao X, Yang X, Wang H. F-BAR family proteins, emerging regulators for cell membrane dynamic changes-from structure to human diseases. J Hematol Oncol. 2015;8:47.

36. Abraham E, Beninson LA, Brown PN, Loughridge AB, Saludes JP, Maslanik T, Hills AK, Woodworth T, Craig W, Yin H, Fleshner M. Acute stressor exposure modifies plasma exosome-associated heat shock protein 72 (Hsp72) and microRNA (miR-142-5p and miR-203). PLoS One. 2014;9(9):e108748.

37. Zhang L, Valencia CA, Dong B, Chen M, Guan PJ, Pan L. Transfer of microRNAs by extracellular membrane microvesicles: a nascent crosstalk model in tumor pathogenesis, especially tumor cell-microenvironment interactions. J Hematol Oncol. 2015:8:14.

38. Fabbri M, Paone A, Calore F, Galli R, Gaudio E, Santhanam R, Lovat F, Fadda P, Mao C, Nuovo GJ, Zanesi N, Crawford M, Ozer GH, Wernicke D, Alder H, Caligiuri MA, Nana-Sinkam P, Perrotti D, Croce CM. MicroRNAs bind to Tolllike receptors to induce prometastatic inflammatory response. Proc Natl Acad Sci U S A. 2012;109(31):E2110-6.

39. Sevin M, Girodon F, Garrido C, de Thonel A. HSP90 and HSP70: implication in inflammation processes and therapeutic approaches for myeloproliferative neoplasms. Mediators Inflamm. 2015;2015:970242.

40. Wen W, Liu W, Shao Y, Chen L. VER-155008, a small molecule inhibitor of HSP70 with potent anti-cancer activity on lung cancer cell lines. Exp Biol Med (Maywood). 2014;239(5):638-45.

41. Lin R, Wang S, Zhao RC. Exosomes from human adipose-derived mesenchymal stem cells promote migration through Wnt signaling pathway in a breast cancer cell model. Mol Cell Biochem. 2013;383(1-2):13-20.

42. Cao $Y$, Sun Z, Liao L, Meng Y, Han Q, Zhao RC. Human adipose tissuederived stem cells differentiate into endothelial cells in vitro and improve postnatal neovascularization in vivo. Biochem Biophys Res Commun. 2005;332(2):370-9. 